\title{
Design and research of Chinese folk arts and crafts show
}

\author{
Yao Ding ${ }^{1, a^{*}}$ \\ ${ }^{1}$ Department of Chinese Language Literature, MinJiang University, Fuzhou, Fujian, 350121, China \\ aemail: dingyao1971@126.com
}

Keywords: Folk crafts; subdivision; brand; packaging; design Strategy

\begin{abstract}
By analyzing the bottlenecks encountered in the development of today's era of traditional arts and crafts, and the promotion of the use of exclusion to find a breakthrough point, to improve the plight from the side. Experience-centric interactive virtual presentation is interactive, immersive, real-time, with actual situation, imagination, fun, etc., to make up for the shortcomings of the existing traditional handicrafts show the drawbacks of existing impressions, can not attract the audience, resulting in the loss of audience. This paper proposes innovative interactive virtual presentation joined traditional handicrafts on display, revolutionized the traditional arts and crafts display mode also broadens the application field of interactive virtual show.
\end{abstract}

\section{Introduction}

Chinese craft civilization for thousands of years, during the birth and evolution of numerous types of arts and crafts, and formed a unique and huge folk craft culture system [1]. Folk art is widely distributed in China, with folk custom, tradition and geographical features, covering all aspects of daily life, including apparel and clothing accessories, food, food utensils, weaving, dyeing embroidery, bamboo and rattan Liu grass weaving items, interior decoration material, toys, holiday items, etc., mostly living necessities $[2,3]$. Chinese folk art color different from the Western conditions, but also with the East is quite different from its natural color decorative color is not in the traditional sense, but a color system and the concept of the five elements of color images color folk artist's subjective consciousness, it Evolution is formed from the original Chinese yin and yang philosophy. Chinese folk art is a decorative color theme, perfect show the people from the heart with color decorating style. Decorative concept is divergent rarely object limitations and restrictions on the choice of colors is also more casual [4]. Chinese Folk Art Colors is an objective things highly refined crystals were refined to match the color, sometimes in order to highlight a layer connotation even change the color of the real thing, such as Chinese folk art of paper cutting, folk artists will usually only one choice colors, and then use this color for color creation, completely abandoned the thing itself, color paper-cut artists according to their overall experience and self-perception of things, creating a subjective image of the idealized imagery works [5-7].

From people with color instinct, the simple use of color performance practices imitate the color of external things than this means the effect is more obvious, so Chinese folk art paintings usually have a natural and vivid colors have come out to show the vitality of the real original thing color [8]. Color is a human visual perception, one received from the outside world information mainly through the visual organ, then into the brain to preserve memories for all the visual image to the outside world, such as the shape of the object, space, location, and their boundaries and differences by color and shading to reflect the relationship. The sensitivity of the human visual impression of color make more artistic charm amplification status has dominated. Chinese Folk Art Color is not a form of primitive art artificial legendary imagination, wide even have the opportunity to covertly romantic, mysterious and seductive inspiration, have a distinct sense of the Chinese nation. The rapid development of modern social and economic and cultural spiritual and material living standards rising six are beginning to pay more attention to living space, the environment and the use of various types of activities and Aesthetic Functions and proposed updates, and higher requirements and therefore, 
China Folk Art combined color elements and modern interior design and creative display is color elements of Chinese folk art heritage and excellent application [9].

This impulse makes the government and all levels of interest related organizations rush to launch a number of folk arts and crafts industry projects, but in the end found that the effect is not ideal, even a serious negative impact. These operators and promoters did not detail the scientific and Chinese folk handicrafts and brand management division and be led to indiscriminate herd phenomenon. Some suitable brand and industrialization of folk arts and crafts are not appropriate and adequate development, the development path of some of the folk art is not suitable for industrial and branded deviation. Thus, we must first identify which is the object to be protected, and which can be commercially or can be transformed industrialization. To rational allocation of resources, it should be broken down according to the characteristics of the brand and folk art scientific classification of brand management.

\section{Origin and Development of Chinese Traditional Arts and Crafts}

In primitive society, human beings in order to survive to create a tool, which is the earliest stage of artifacts, but also the origin of arts and crafts. Some natural objects such as wood, bone, stone, flowers, etc [10]. After polishing process simple humanity would become a tool for improving the living environment, and they use these craft to hunt and protect themselves against the cold winter, etc., this period did not say the beauty of handmade goods, solely for practical and creation, which is human survival instinct is the manual labor into the entity tool process. The human ability to transform nature experience with age, from weak to strong development of crafts have also gone from simple to complex, from coarse to fine, from a single to a wealth of process (Fig. 1).

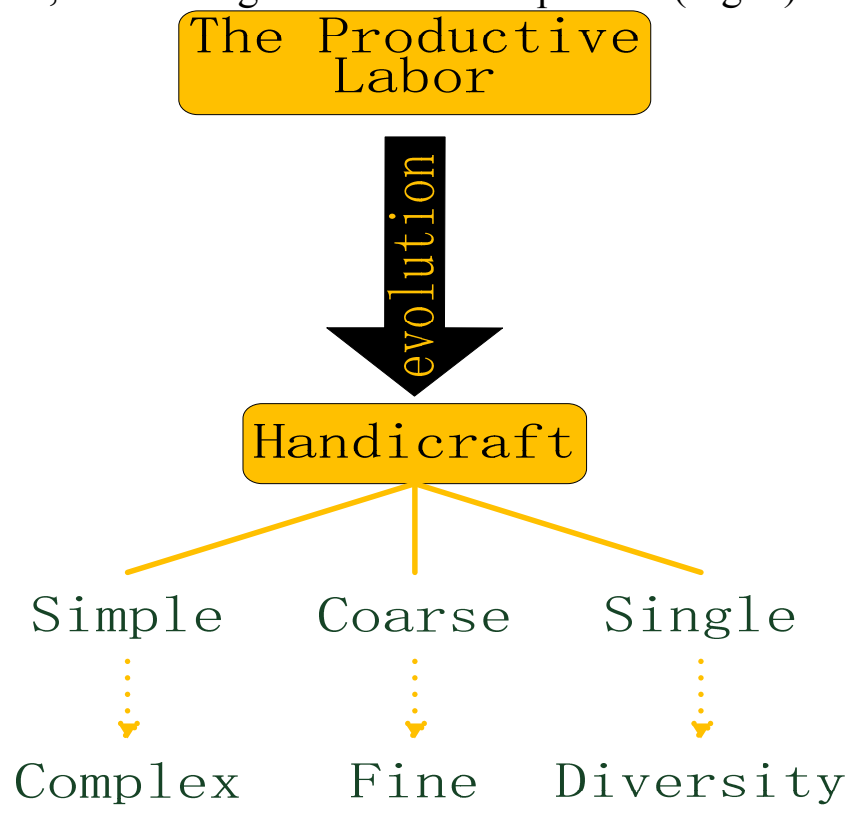

Fig. 1. Evolution of crafts

Chinese society in 1840 and was produced before the formation of life corresponding traditional process. Basic necessities play self-sufficiency, self-contained, handed down for thousands of years almost no much change. In China's feudal social system, development of handicrafts unprecedented prosperity, due to technical underdeveloped, when most people rely on manual labor to live, crafts provided most of the necessities of life. Especially women, patriarchal ideology so that women can only stay at home at home, learning female red, then red female judge whether a woman is good or bad is good important reference. In the meantime, silk, embroidery, gold, jade, lacquer, wood, cloth and other industries is quite superb skills, a lot of craftsmen with their own hands to create an outstanding work of art has spread, while leaving a brilliant precious handicraft culture. 


\section{Chinese folk crafts brand segmentation}

Product segments projecting out of the Chinese folk art brands abound in China, which is based on the range of products, the nature of products, product quality and value, product use, product user, product origin produced. As Jingdezhen ceramics, batik Guizhou Miao embroidery, Fujian lacquer line carving, Nantong blue calico, Yangliuqing, Guangzhou, "three birds with one color," Chaozhou porcelain, pottery and Foshan woodblock New Year pictures, Zhaoqing Duan, Chaozhou woodcarving belong this type.

Folk art with a certain brand of personalized features including prominent producers or craftsmen personal characteristics of the brand and an outstanding historical figures, mythological figures such as personalized brand. National arts and crafts masters have known, competing on the market in recent years become the object of pursuit. Such as national non-genetic order of Nantong blue calico, within Chinese Arts Shaanxi painted pots, boutique Yixing teapot Institute, Jiangsu Arts and Crafts master Shen Shou embroidery, provincial non-genetic order of Guizhou batik, national non-genetic order of high imitation Tang Dynasty, there are many national master craftsman cloisonne, Tian Huang, Shoushan stone, embroidery, bamboo, wood carving and other works.

\section{Technology Value}

Science and technology in the less developed ancient crafts also a technology live, it contains the infinite wisdom of working people. It is not just a simple hand martial arts, but the crystallization of the wisdom and dexterity. As early as the Neolithic primitive society, Banpo people know how to use clay pottery, is also able to draw on a simple totem, now it seems simple pottery techniques at the time it is a very advanced technology, and is also regarded as pedigree pottery industry. Later Jingdezhen porcelain master, select the furnace pigment ratio, are particular tool, only fully mastered the technology to make a superb blue and white porcelain. Every glorious beautiful handicrafts are behind the need for technical support, where the technology is not only refers to the science and technology, but also the skills and processes. Art methods in traditional crafts included, bring us in the United States while giving a modern inspiration and reference.

The rapid development of science and technology, arts and crafts and some technology spread so far little has changed, not their pace to keep up with modern, but this technology is in use today are not inappropriate, such as Japan's Shan gold craft, refinishing paints into distribution ratio and patch craft still in use, after the repair finished simple trace gorgeous, even after repair, kept changing the original is not the same style, it is necessary to respect the original but also beautiful, really requires a lot of skill (Fig. 2).

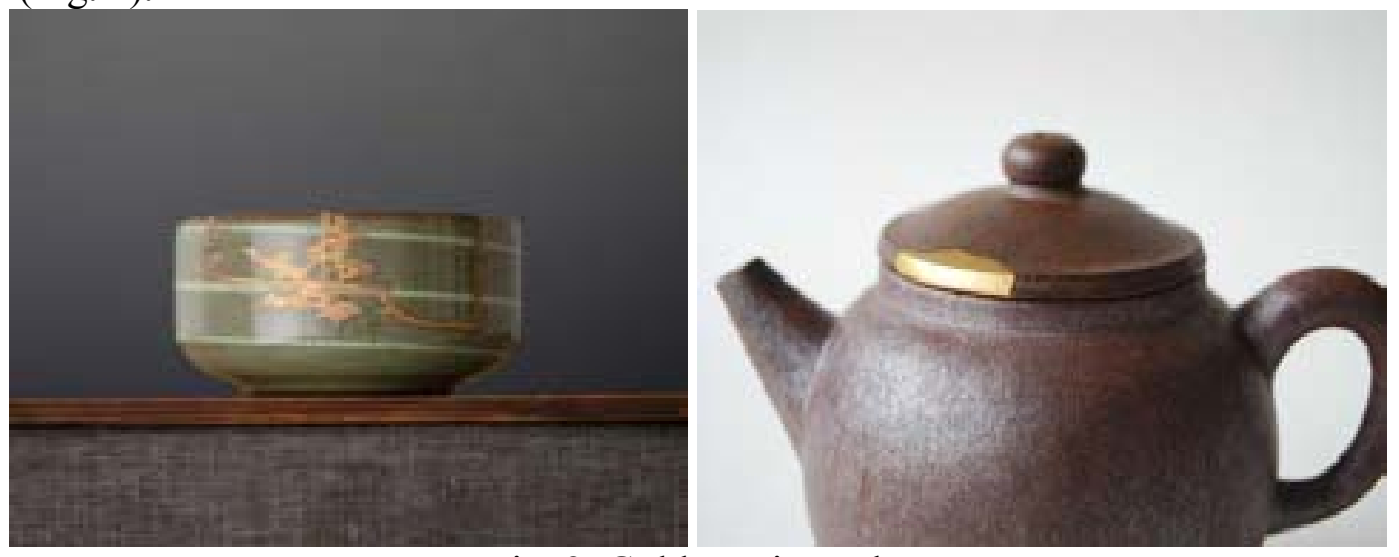

Fig. 2. Gold repair works

Ming Dynasty furniture tenon joint structure between each bite uneven structure, very solid and durable. This structure made furniture more firmly connected than nails, effectively prevent the furniture around, twisting. Use tenon structure crafted Ming furniture has spread despite vicissitudes, but the wood is still as ever, if you use nails or glue connection, perishable wood aging. The structure 
has been in use ever since, in wooden buildings, wooden furniture, a very wide field of application, some of the design work also use a tenon joint structure combines the modern aesthetic, to create a unique flavor (Fig. 3).
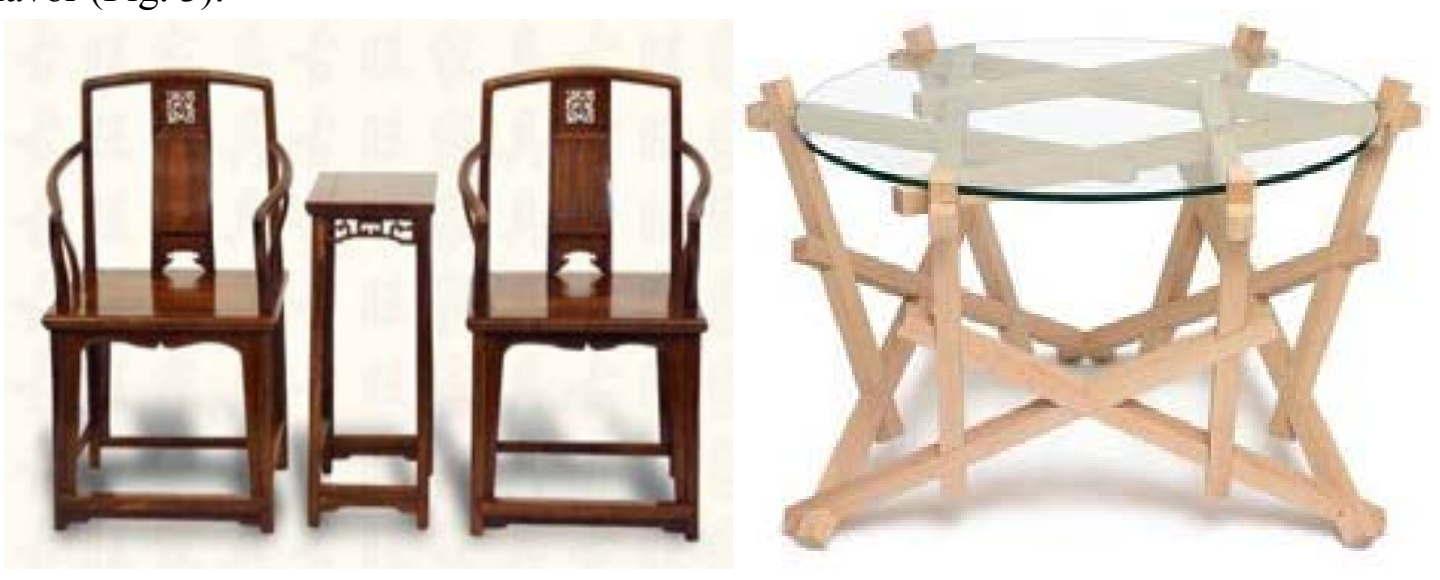

Fig. 3. Tenon joint structure

In the agricultural economy, manual labor is the main productive forces, most of the labor in life are done by hand. Busy when people put the focus was on farming, slack and stopped to do some fragmentary gadgets supplement the family income, handicrafts was a large part of economic resources. Applicability weakened, reducing demand to some extent, affected the purchases of handicrafts, so part of the everyday objects of arts and crafts faded stage. But with social development, people's spiritual pursuit to improve and stimulate the rise of tourism, the tourism industry has brought a large number of foreign tourists, promote the development of the local characteristics crafts.

\section{Interactive virtual exhibition design and Value}

Interactive virtual display is a two-way communication display mode, the user to interact through specific media and display objects interactively main limbs, facial expressions, gestures, language, sound, etc. When the media receive the information transmitted user objects are displayed in a visual, auditory, tactile, olfactory five senses user feedback, the exchange of information in the users get a surprise, fun, touching, sad emotional experience, etc. (Fig. 4).

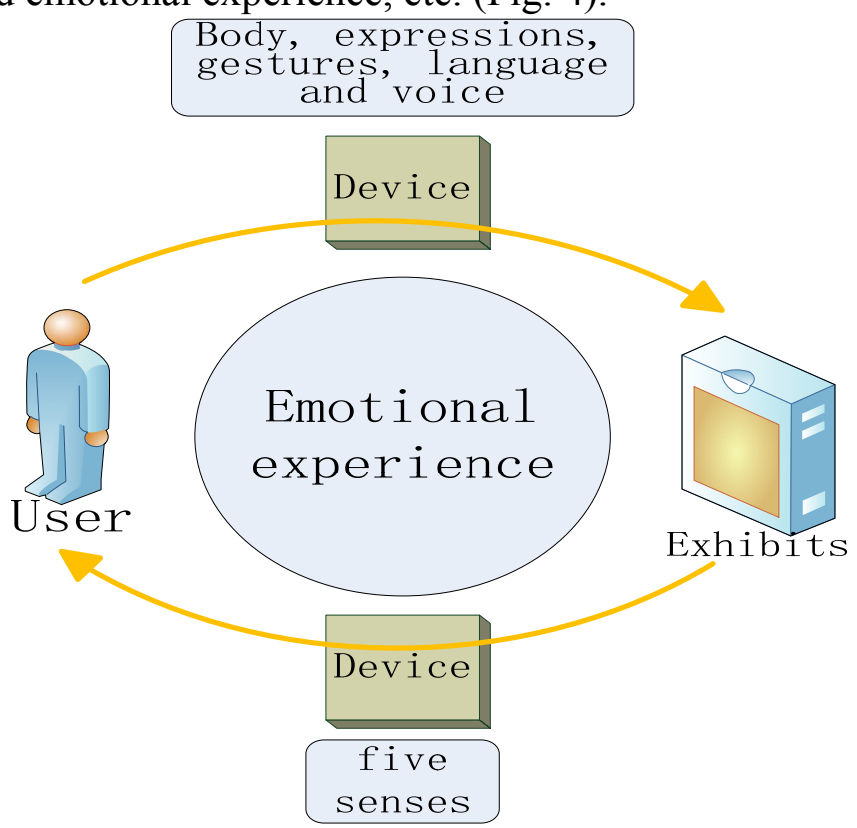

Fig. 4. Interactive virtual presentation mode 
It is interactive, immersive, real-time, with actual situation, interest and so on. Interactive virtual presentation emphasized the main user participation, attention to user experience. It has changed the traditional display can only rely on one-way transmission of auditory and visual information in the display process, build an interactive virtual exhibition platform to interact with virtual items, user feedback and timely, highly interactive. It provides video images of text except outside the new man-machine interfaces, from space to time constraints, is a very liberal dynamic information exchange platform.

Users are in the virtual reality world of their own existence realism experience effect it produces immersive display design breaks through the traditional user by means of a specific device and can even enjoy the "play" products. Ideal User Language immersion is a virtual world, but it felt like in the real world events, however rotate the camera, always follow the virtual scene sight transformation, allowing users to distinguish between true and false.

\section{Summary}

China's current lack of folk art product or brand identity design system science, folk art homogenization widespread. Many folk crafts personalized or do not have differentiated features, less attractive; many historical and practical reasons, the traditional folk crafts and brand management behind these serious impact on folk art and industrial brand. Folk crafts brand in the segment, based on the correct use of brand packaging design strategy will help to create brand equity. Scientific management of the folk handicraft brand promotion of cultural industry development and prosperity folk art culture, shaping brand culture oriented city has a very important role.

\section{References}

[1] $\mathrm{Wu} \mathrm{W}$. The Integration of the 3D Printing Technology and Traditional Chinese Handicrafts[C]//Proceedings of the 22nd International Conference on Industrial Engineering and Engineering Management 2015. Atlantis Press, 2016: 293-303.

[2] Schroeder J, Borgerson J, Wu Z. A brand culture approach to Chinese cultural heritage brands[J]. Journal of Brand Management, 2015, 22(3): 261-279.

[3] Wan Y K P, Chan S H J. Factors that affect the levels of tourists' satisfaction and loyalty towards food festivals: a case study of Macau[J]. International journal of tourism research, 2013, 15(3): 226-240.

[4] McCartan S, Verheijden R, Roy J, et al. Design-Driven Innovation of a High Speed Art Deco Superyacht Coastal Cruiser for the Chinese Market'[C]//The Royal Institution of Naval Architects, Design Conference: Design and Construction of Super \& Mega Yachts, Genoa, Italy. 2013: 8-9.

[5] Klamer A. Crafting Culture: The importance of craftsmanship for the world of the arts and the economy at large[J]. June. http://www. klamer. nl/docs/crafting. pdf, 2012.

[6] Klamer A. Crafting Culture: The importance of craftsmanship for the world of the arts and the economy at large[J]. June. http://www. klamer. nl/docs/crafting. pdf, 2012.

[7] Klamer A. Crafting Culture: The importance of craftsmanship for the world of the arts and the economy at large[J]. June. http://www. klamer. nl/docs/crafting. pdf, 2012.

[8] Hou Y. The Civilization Slept in the Land--The Outlook on Heritage and Innovation of Folk Art from the Xiao Guo Clay Sculpture[C]//2014 International Conference on Global Economy, Finance and Humanities Research (GEFHR 2014). Atlantis Press, 2014.

[9] Cunningham S D, Potts J D. Creative industries and the wider economy[J]. The Oxford Handbook of Creative Industries, 2015: 387-404.

[10]Lin Y J, Chen J L, Lin P H. The Cognition of Curatorial Strategies for Interpreting Localism[J]. US-China Education Review, 2015, 5(12): 806-818. 